\section{Pacific Northwest}

National Laboratory

Operated by Battelle for the

U.S. Department of Energy

\title{
Parris Island Wastewater Treatment Plant SCADA Upgrades Final Report
}

\author{
R. J. Meador \\ D. D. Hatley
}

February 2004

Prepared for the U.S. Department of Energy

under Contract DE-AC06-76RL01830

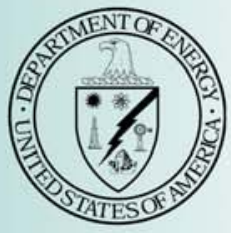




\title{
DISCLAIMER
}

This report was prepared as an account of work sponsored by an agency of the United States Government. Neither the United States Government nor any agency thereof, nor Battelle Memorial Institute, nor any of their employees, makes any warranty, express or implied, or assumes any legal liability or responsibility for the accuracy, completeness, or usefulness of any information, apparatus, product, or process disclosed, or represents that its use would not infringe privately owned rights. Reference herein to any specific commercial product, process, or service by trade name, trademark, manufacturer, or otherwise does not necessarily constitute or imply its endorsement, recommendation, or favoring by the United States Government or any agency thereof, or Battelle Memorial Institute. The views and opinions of authors expressed herein do not necessarily state or reflect those of the United States Government or any agency thereof.

\author{
PACIFIC NORTHWEST NATIONAL LABORATORY \\ operated by \\ BATTELLE \\ for the \\ UNITED STATES DEPARTMENT OF ENERGY \\ under Contract DE-AC06-76RL01830
}

Printed in the United States of America

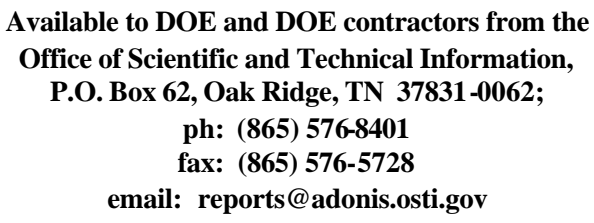

Available to the pu blic from the National Technical Information Service, U.S. Department of Commerce, 5285 Port Royal Rd., Springfield, VA 22161 ph: (800) 553-6847 fax: $(703) 605-6900$

email: orders@ntis.fedworld.gov online ordering: http://www.ntis.gov/ordering.htm (3) This document was printed on recycled paper. 


\title{
Parris Island Wastewater Treatment Plant SCADA Upgrades Final Report
}

\author{
R. J. Meador \\ D. D. Hatley
}

February 2004

Prepared for the United States Marine Corps

Facilities Maintenance Division

Marine Corps Recruit D epot/ ERR

Parris Island, South Carolina

Project 24834 Task 5

Under a Related Services Agreement with the

U.S. D epartment of Energy

Contract DE-AC06-76RL01830

Pacific Northwest National Laboratory

Richland, Washington 99352 


\section{Summary}

Marine Corp Recruit Depot (MCRD), Parris Island, SC, home of the Eastern Recruiting Region Marine Corp Boot Camp, found itself in a situation common to Department of Defense (DOD) facilities. It had to deal with several different types of installed energy-related control systems that could not 'talk' to each other. This situation was being exacerbated by the installation of a new and/or unique type of control system for every new building being constructed or older facility that was being upgraded. The Wastewater Treatment Facility (WWTF) and lift station controls were badly in need of a thorough inspection and a new Supervisory Control and Data Acquisition (SCADA) system upgrade to meet environmental, safety, manpower, and maintenance concerns. A project was recently completed to implement such a wastewater treatment SCADA upgrade, which is compatible with other upgrades to the energy monitoring and control systems for Parris Island buildings and the Pacific Northwest National Laboratory (PNNL) Decision Support for Operations and Maintenance (DSOM ${ }^{\circledR}$ ) system installed at the Central Energy Plant (CEP). This project included design, specification, procurement, installation, and testing an upgraded SCADA alarm, process monitoring, and display system; and training WWTF operators in its operation. The ultimate goal of this and the other PNNL projects at Parris Island is to allow monitoring and control of energy and environmental components from a central location.

The automation provided by the SCADA upgrades allowed the WWTF supervisor to eliminate backshift and weekend staff and to shift his resources from 24 hour daily operations to preventive and proactive maintenance, resulting in a better operating plant over the long term. The main plant WWTF upgrades were completed in the spring of 2002 with the antenna work completed in 2003. Automation of the WWTF has actually reduced operational manpower requirements by the equivalent of three full time staff. Additional projects are underway at MCRD Parris Island to ensure all CEP, SCADA, and building control systems are compatible, can communicate with each other, and can be accessed from a central location or the Parris Island local area network (LAN). 


\section{Table of Contents}

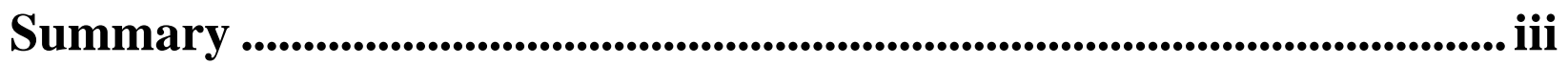

1.0 Introduction ........................................................................................................ 1

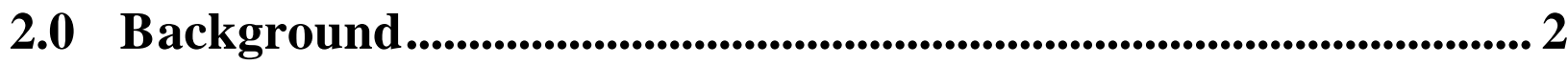

3.0 WWTF Upgrades............................................................................................ 4

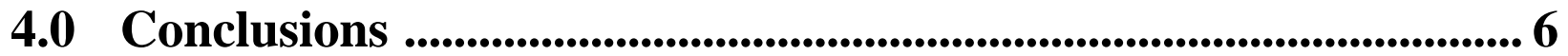




\subsection{Introduction}

Parris Island is one of the most visited military facilities in the world, hosting more than 100,000 visitors a year. It is the home of the Eastern Recruiting Region and recruit training for all male marines east of the Mississippi River and all female marines nation-wide. A staff of over 2,500 Marines, Sailors and civilians to keep Parris Island operational. A Wastewater Treatment Facility (WWTF) with 38 associated lift stations serves the entire complex. The level of concern over the WWTF's potential for a major environmental discharge had been increasing for several years. The remote lift station control panels in the field had been failing at an increasing rate due as a result of age, moisture penetration, and heat deterioration of the electronic packages. At any one time, several of the alarm systems may be out of service. This left the WWTF at further risk for spills and environmental concerns. System age and resulting deterioration had approached the point where continuous repair costs were exceeding the cost of replacement.

PNNL was funded by USMC HQ to design, procure, install, test and train WWTF operators on an upgraded SCADA alarm and process monitoring system. This upgraded system needed to be capable of monitoring conditions and alarms at the WWTF as well as the CEP, and provide alarm notification to assigned staff. The system replaced all of the monitoring processor systems and radio links that were previously associated with the lift stations. It upgraded the hardwired monitoring system associated with the wastewater plant itself. The system provides all of the information to two workstations for operator monitoring and handling of normal processes and emergency situations. One station is located at the WWTF, and the other in the Central Energy Plant (CEP) operations room. The system is associated with the current Decision Support for Operations and Maintenance (DSOM) system installed in the CEP. This allows the CEP operations personnel to provide backup and off-shift monitoring for alarms and to provide any assistance as required. 


\subsection{Background}

The Parris Island Depot rises a maximum of 32 feet above sea level, and operates a single secondary WWTF. The WWTF was originally constructed in 1947. Wastewater generated on Parris Island is conveyed to the treatment plant via 33 lift stations. Five additional lift stations are located at and used by the treatment plant. The collection system consists of approximately 34 miles of gravity and forced flow lines. The treatment plant is a trickling-filter type plant with, a current operating capacity of 1.5 million gallons per day $(\mathrm{mg} / \mathrm{d})$ and discharges through an outfall pipeline extending into the Beaufort River. The plant operates under a permit from the South Carolina Department of Health and Control.

Parris Island has conducted a rainwater infiltration and inflow study and continues to implement corrections and improvements to the collection system to reduce the amount of inflow and infiltration conveyed to the treatment facility by the system. Corrections implemented include slip-lining pipes and installing manhole cover inserts.

The WWTF has undergone numerous process changes since it was first installed. Plant influent is slightly septic in nature as a result of high detention times in portions of the distribution system. The influent average annual daily flow is 705,000 gallons per day. Although the original design capacity of the WWTF was $3.0 \mathrm{mg} / \mathrm{d}$, the current overall operational capacity of the treatment facility is $1.5 \mathrm{mg} / \mathrm{d}$ as a result of the repiping of two of the original four clarifiers to provide intermediate clarification processes. Because the primary clarifiers are now split, each clarifier is more important in the overall treatment process. A failure or downtime of the primary clarifiers is more likely to cause a direct impact or interference with the overall treatment capability of the facility. Process redundancy and backup storage capacity provided in the original design either has been reduced or removed from the system.

Prior to upgrading, the WWTF SCADA system was a Seaboard-style telemetry monitor for the 32 remote lift stations and the main processing area (one lift station has been added since the project started to make 33). The SCADA system was in a deteriorated condition. All of the field lift stations were either degraded or had failed. The multiple failures of the system were attributed to humidity, age, and lightning damage. The system was based on an older alarm monitoring electronic board, originally designed for bank alarm reporting. These units were mounted in lift stations with high humidity and poor ventilation. Because the system is more than 20 years old, degradation was apparent on boards, connectors, and communications systems. Parris Island is located in a high lightning strike area that has resulted in additional damage to several boards. Lift station local controls were still functioning, but alarm reporting was not reliable. At the main plant, level and alarm functions within the different systems had deteriorated with age and use to approximately $50 \%$ usability. Most of this deterioration was the result of aging phone lines that were originally used for communications. Alarms were transmitted over existing phone lines, and this system had also deteriorated as a result of wind and moisture penetration. The transmitted alarms were basically limited to sump high level and emergency generator run status. Alarms were routed to an annunciation panel in the main 
operator's office at the WWTF. When the office was not occupied, no alarms were automatically routed from this office to alert staff. This situation could result in a slow response to abnormal or emergency conditions. It was realized that utilizing the DSOM technology, significantly more real time information, such as the measurement of tank levels, volumes, pump capacity and flows could be obtained and subsequently utilized for diagnostic functions. 


\subsection{WWTF Upgrades}

PNNL performed a thorough inspection of the comple te system to clearly establish the baseline condition. The inspection included all wiring, sensor and monitoring devices, controllers, telemetry, and SCADA software. This information was used to develop a master plan for modification, upgrade, or replacement of part or all of the lift station control system. PNNL staff designed SCADA control cabinets to be built and installed in each lift station. Lord \& Company, Inc., instrumentation and control systems specialists, were contracted to build, install and commission the cabinets. New UL labeled weatherproof control panels were made up with Allen Bradley Micro 1000 programmable logic controllers (PLCs), power supplies, and interface relays for pump monitoring and override float operations in case of PLC failure. Communications were upgraded by including a Johnson radio communications system (described in more detail below) interface in each cabinet to establish data transmission with the main radio in the WWTF operator's office. Uninterruptible power supplies were provided in each of the 32 cabinets for backup power of the control and radio links to continue monitoring during power outages.

The wastewater treatment process was analyzed to see if some of the alarm or monitoring points should be changed from solely high level to full level monitoring. This change would provide better process control along with warning alarms before critical levels are reached. It would also provide a significant reduction in abnormal event response time, with a corresponding reduction in environmental risk. Lord \& Company, Inc. installed a PNNL-specified Milltronics ultrasonic level detection system in each remote lift station sump to increase monitoring capability. The existing float control systems were reset and used as alarm and backup control.

PNNL engineers used a Rockwell Systems commercialoff- the-shelf (COTS) software program for the WWTF application. A Rockwell Automation software program, RSView32 Version 6.3, running under Windows NT4.0, SP4, was used to work with the existing DSOM software at the CEP. This allowed an interface between the CEP and WWTF operator's office for alarm response and monitoring capabilities. The graphical user interface (GUI) was designed and set up by PNNL staff for simple point-and-click operation by the WWTF operators. An administrative level of security was established to allow supervisory personnel the ability to change pump automatic switchover setpoints and level alarm set points from the WWTF operator's console. All the lift stations and their associated alerts and alarms are accessible from one main screen display. Figures $1-13$ at the end of this document show various aspects and capabilities of this system.

Each lift station is represented by a graphic depicting sump level, pump status, communications status, and remote generator status under loss of power conditions. The software provides the operators with the ability to trend data, manually start and stop pumps remotely, and change the auto mode sequence for automatic pump start and stop operations. With the supervisory access activated, supervisors can change alarm points, auto pump start and stop points, and level control set points through a simple-to-use set points interface screen. Through active $\mathrm{X}$ trending 
capabilities, operators can easily examine trend data on all values monitored, such as run times, pump amperage, and pump capacity.

Each of the remote terminal units (RTUs) now uses a Johnson Data Telemetry model T-96SR radio unit. The T-96SR is a transparent real-time radio modem designed primarily for SCADA system and telemetry use. A Johnson Data Telemetry model T-BASE/R is used in the Wastewater Treatment Facility operator's office as the "master radio". The T-BASE/R is basically the same unit as the T-96SR radio with an additional port for on- line diagnostics utilizing an existing Government- licensed frequency.

The final step in upgrading the WWTF was to install and tie in instrumentation for monitoring and control of the main wastewater treatme nt plant components to the existing software system that was controlling the lift stations. This allowed the complete process to be monitored and controlled from the WWTF operator's console, with backup monitoring at the CEP during unmanned conditions. This resulted in less environmental risk, higher reliability, and a more effective process for collecting and processing wastewater at Parris Island. PNNL worked with Lord \& Company, Inc., to design, specify, procure, install, and test the new SCADA alarm monitoring and process monitoring system for the main plant and train WWTF operators in its operation. This final phase of the project also provided the addition of an antenna tower to improve communications reliability between the main plant control room and the more remote lift stations. Eight additional PLCs were installed to provide in-process monitoring of values for $\mathrm{pH}$, dissolved oxygen, and temperature at all the important process points, and provided the ability to monitor and control all major process points and their components remotely from a central location. Graphics of each major component were provided to display the information to the operator. Again, all the screens accessible to the operator are intuitive, point-and-click navigation, and so simple to use that they required only minimal training. With the proper security access codes, the supervisor can set various parameters to control lead and lag sequencing of pumps, pump float controls and alarm features; or take manual control of major components from the main office central location.

The final step on the SCADA upgrade project was to upgrade communications by replacing the master antenna and relocating it on a new antenna tower. This last item was successfully completed in the Spring of 2003.

Lord and Company, Inc. provided submittal data for approval and as-built drawings for the completed work so additional details of this installation are available to plant operations and Parris Island engineering staff. Lord and Company, Inc. also provided the operators an Instrumentation and Controls Operation and Maintenance Manual that covers the installed system. Lord and Company, Inc. is located at 2100 Carolina Place Drive, Fort Mill, SC 29708 


\subsection{Conclusions}

The automation provided by the SCADA upgrades allowed the WWTF supervisor to eliminate backshift and weekend staff and to shift his resources from 24 hour daily operations to preventive and proactive maintenance, resulting in a better operating plant over the long term. The main plant WWTF upgrades were completed in the spring of 2002 with the antenna work completed in 2003. Automation of the WWTF has actually reduced operational manpower requirements by the equivalent of three full time staff. Additional projects are underway at MCRD Parris Island to ensure all CEP, SCADA, and building control systems are compatible, can communicate with each other, and can be accessed from a central location or the Parris Island local area network (LAN).

The Appendix includes actual examples of various screen displays designed for the WWTP operators at Parris Island. A short explanation description is also provided. 


\section{APPENDIX}

Examples of Screen Displays Designed for the WWTP Operators at Parris Island 


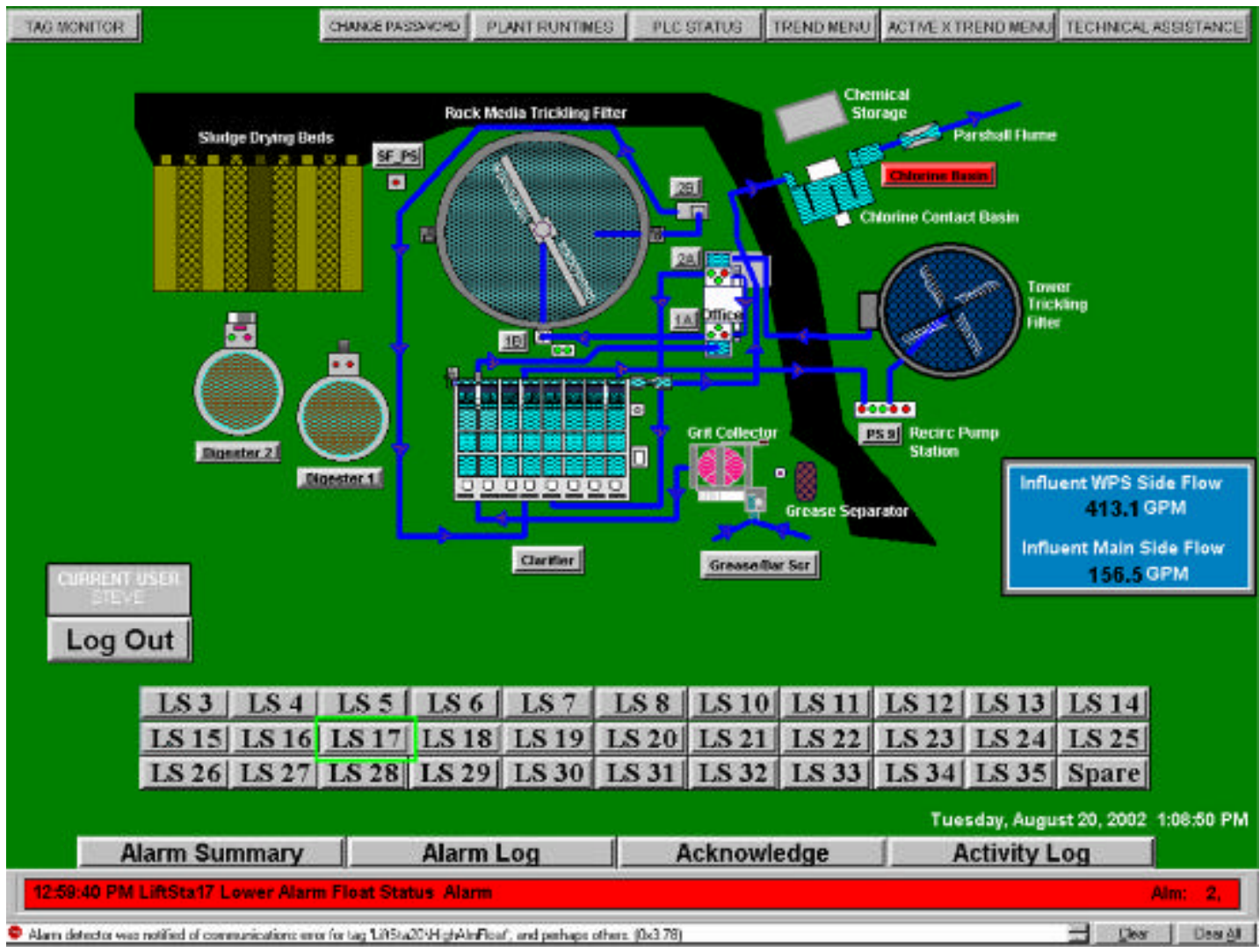

Figure A.1. Wastewater Treatment Facility Overview Screen

This is the main screen display for the WWTF. Any item resembling a button provides access to additional information in the form of a graphic for that component or portion of the process. All operators and supervisors log in and out from this screen. Security levels of access are set by the supervisor and controlled via the login process. All screens are available for access at the WWTF main office computer and the CEP operator's office computer over the Parris Island LAN. Anyone with the proper software and permissions can access this program via the Parris Island Intranet. This screen provides high level information to the operator and the current status of all the major components. For example, the LS 17 button highlighted in green is actually blinking red/gray to indicate the alarm at lift station 17 listed in the red alarm notification band near the bottom of the screen. The Chlorine Basin button is also in red, indicating an existing alarm at the Chlorine Basin has already been acknowledged but has not cleared. 


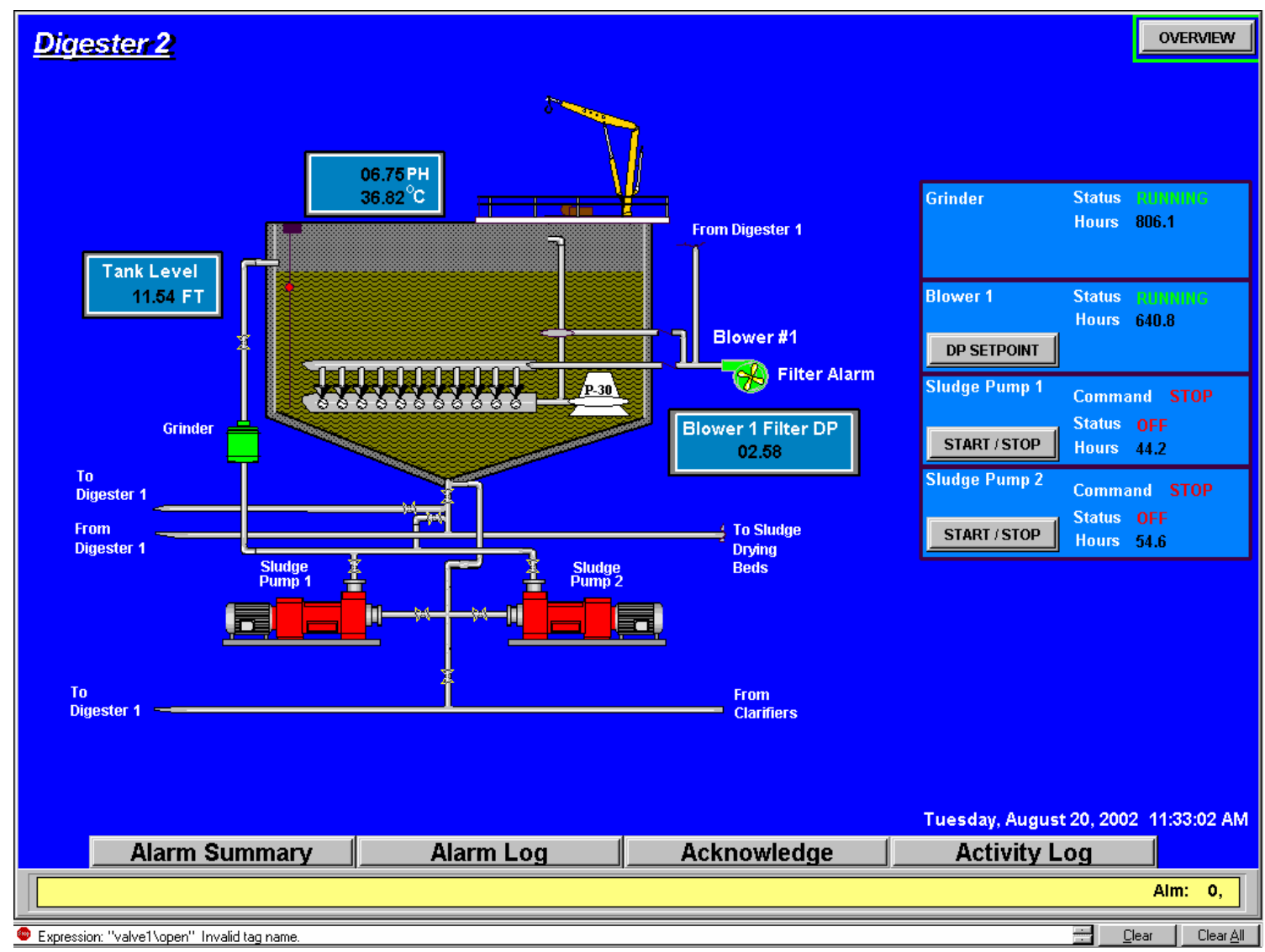

Figure A.2. Digester 2 Screen

Clicking on the Digester 2 button brings up the requested display. This indicates various parameters, instantly showing the status of the digester grinder and blower operation, pumps, tank level and blower filter differential pressure (D/P). Clicking on the instrument readings will also produce easy to manipulate trend graphs for each instrument (example provided in Figure 12). This is true for all instruments in this program. 


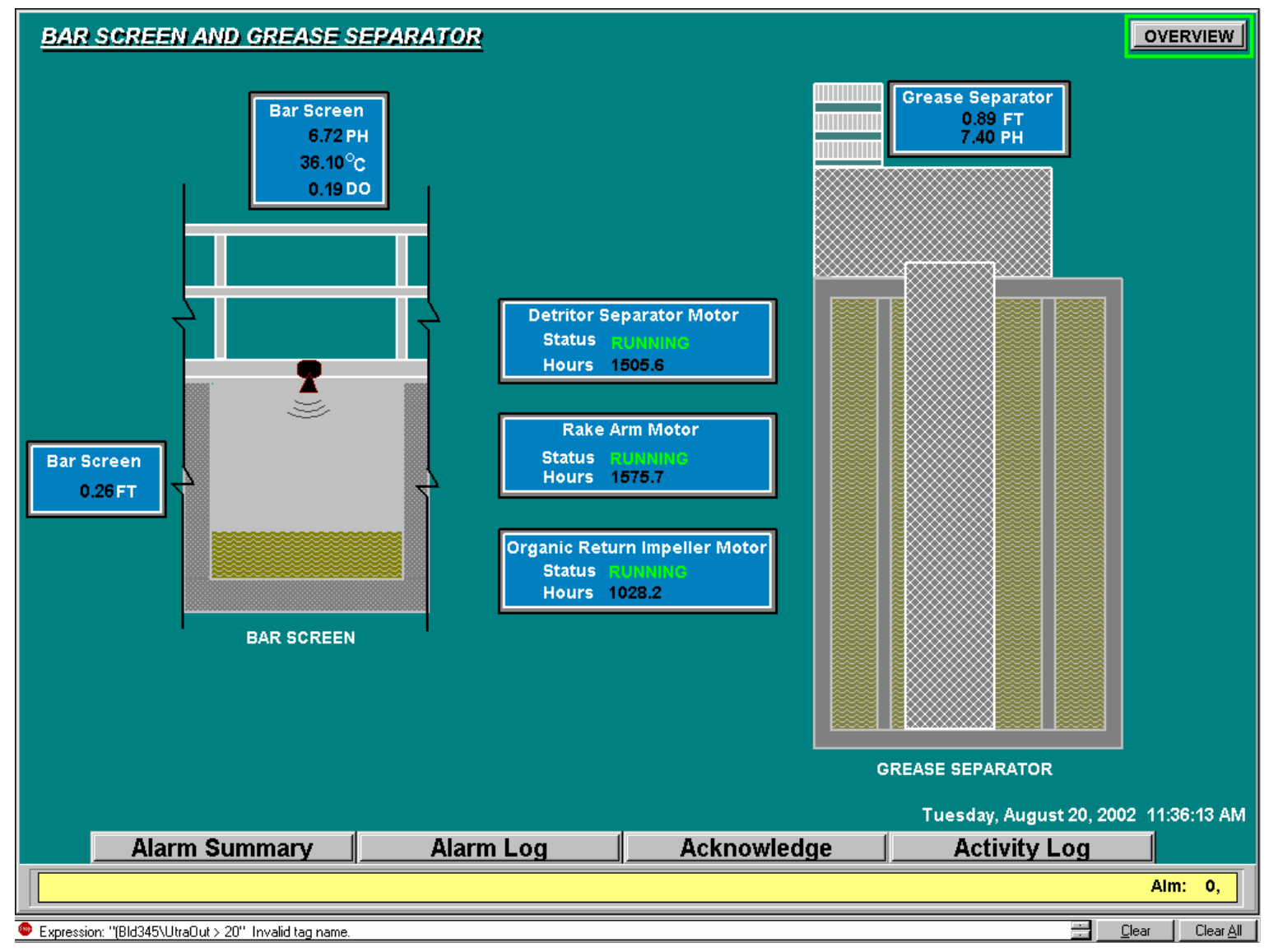

Figure A.3: Grease Separator Display Screen

Display depicts status of the Bar Screen and Grease Separator, where the wastewater first enters the Main Plant processing stream. Bar screen level, $\mathrm{pH}$, temperature and dissolved oxygen (DO) parameters are provided. 


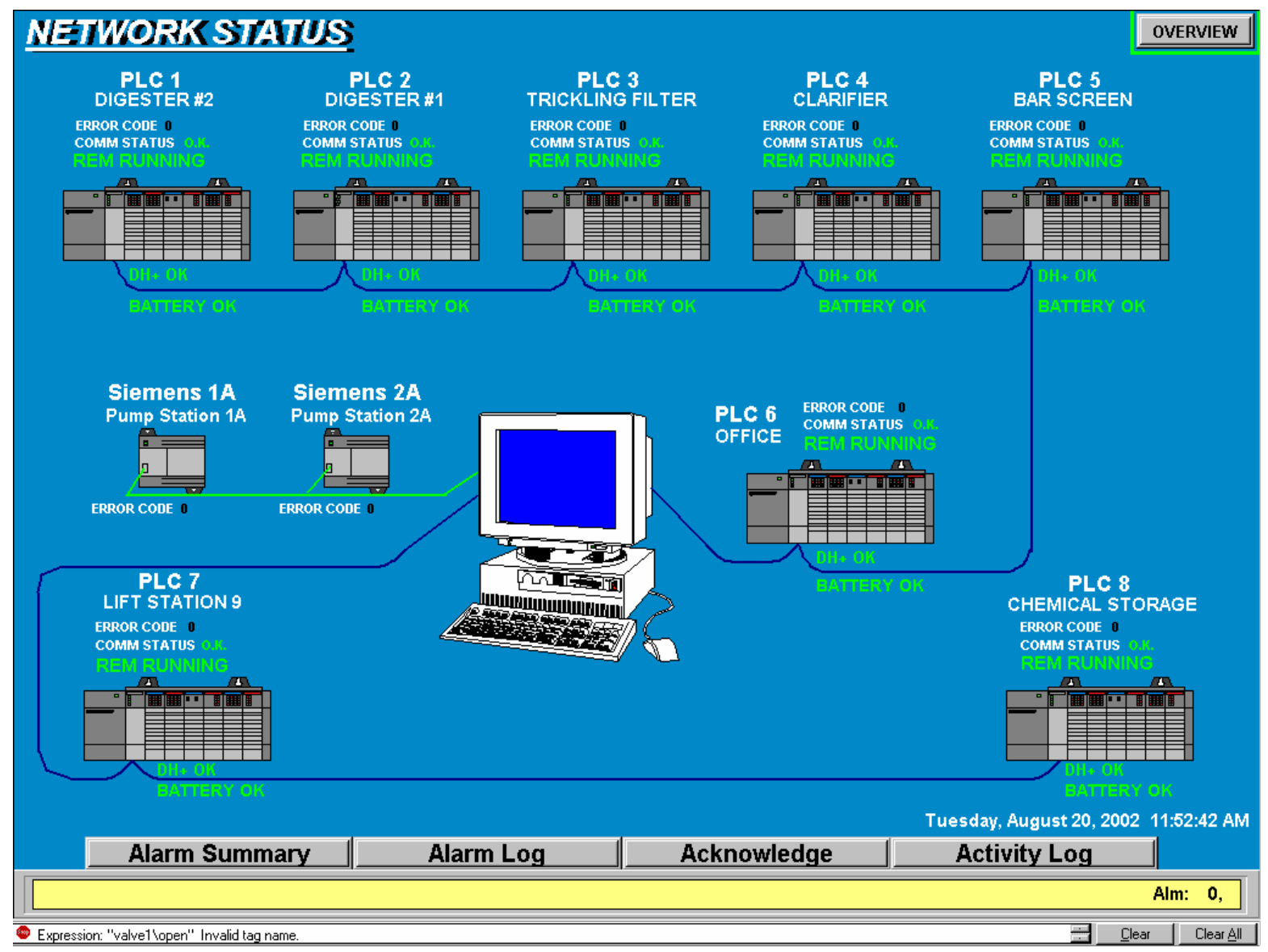

Figure A.4: Programmable Logic Controller Status Screen

Eight PLCs are installed in weatherproof cabinets at critical locations throughout the Main Plant to monitor and control operations. This display gives the operator a quick picture of the Main Plant network status and would allow quick identification and isolation of problems. It also gives the operators a good depiction of how their system data communication system is arranged. 


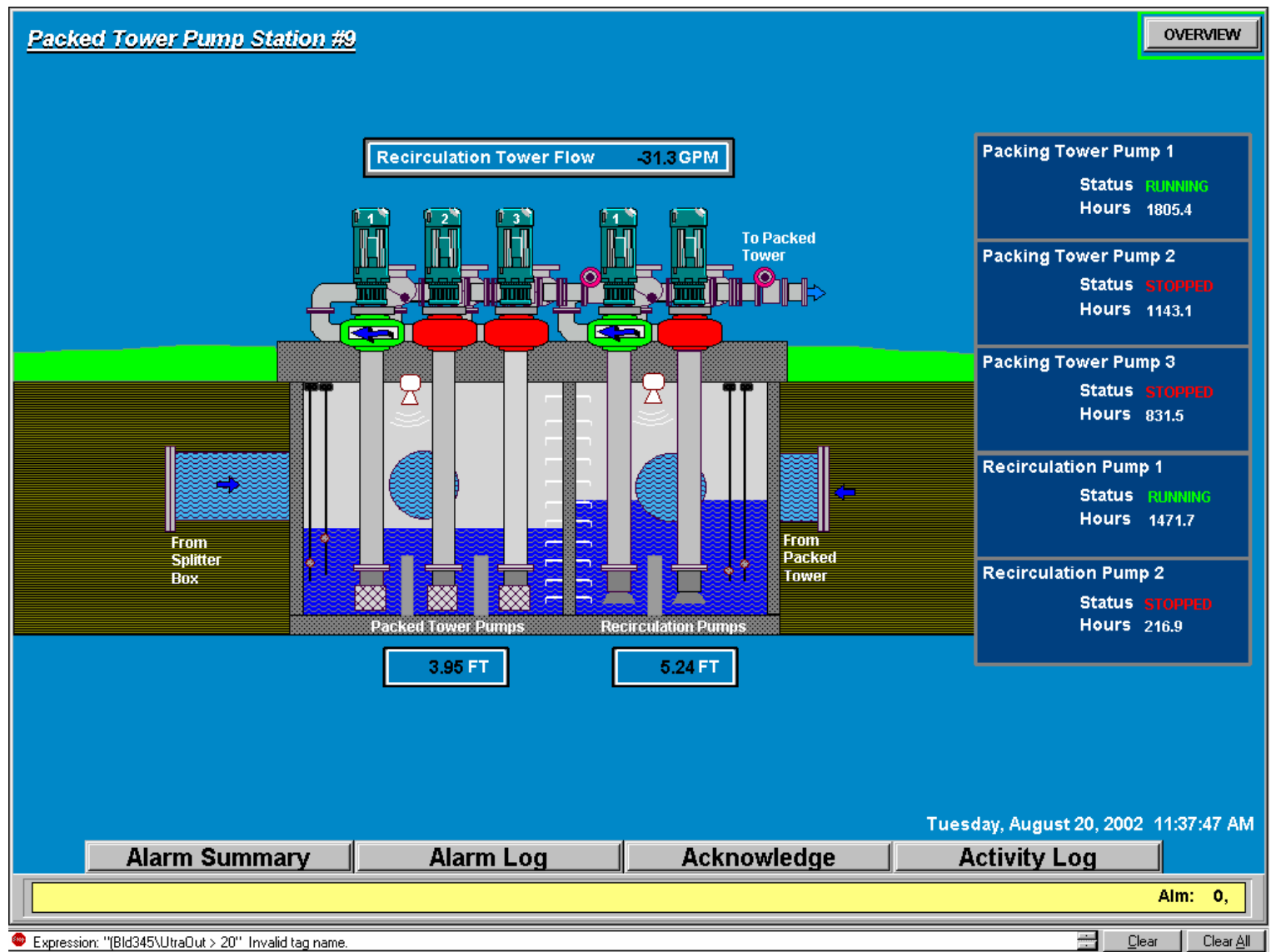

Figure A.5: Pump Station \#9 Display

This display indicates the typical range of information available on a pump station display. Pump station \#9 provides process flow into the packed tower and also provides recirculation flow capabilities. It is easy for the operator to see at a glance what lift station and pump station levels are and what pumps are running. This pump station, as are all the others, is programmed to run in an automatic mode. 


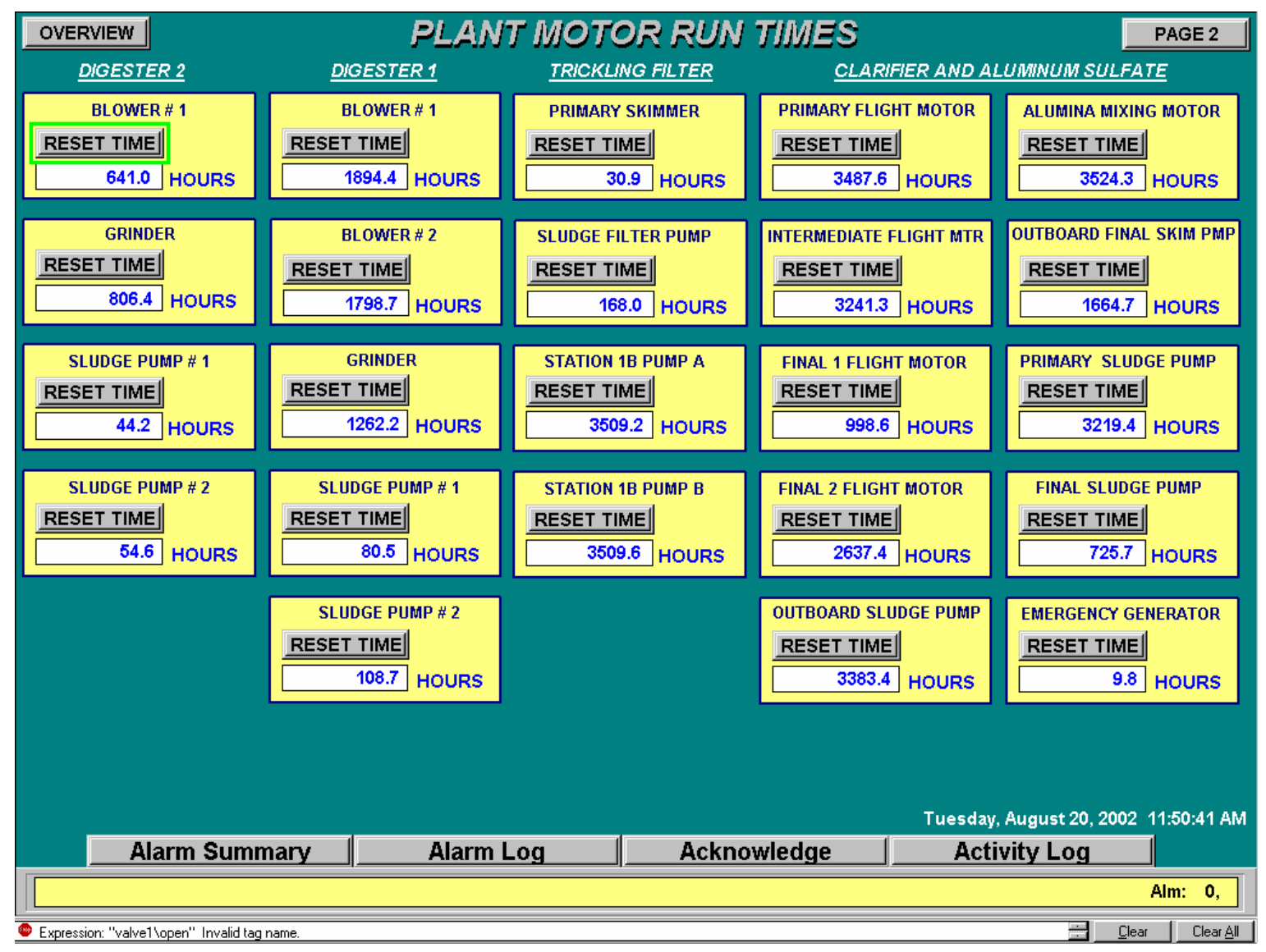

Figure A.6: Pump Motor Run Time Summary

This display (along with page 2 of the screen, accessed with the button in the upper right hand corner) provides a summary of pump run times for the Main Plant components. This allows the operators and supervisors easy access to equipment run time information and provides them with the capability of resetting run times for pumps that are repaired or replaced. 


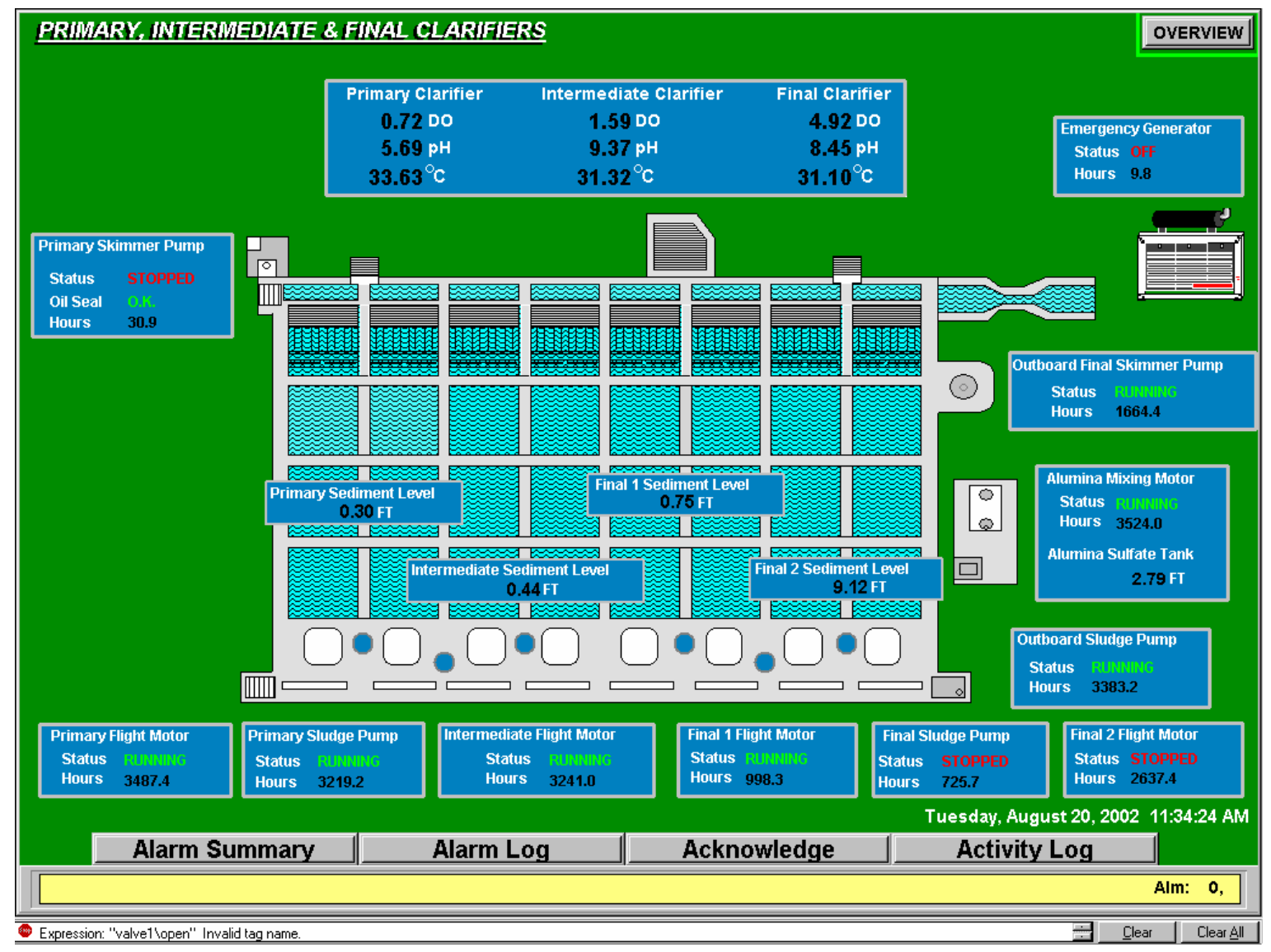

Figure A.7: Clarifier Overview Display Screen

This display shows the status of the clarifier complex chemistry, pumps and motors. Generally, the primary and intermediate clarifiers are used in conjunction with one of the two final clarifiers. The operator can easily get live status of the current process flow because these screens update with live information when open for display. For all components that have an emergency generator available, the status of the emergency generator is also displayed. This is critical information during a loss of power to the Main Plant and lift stations. 


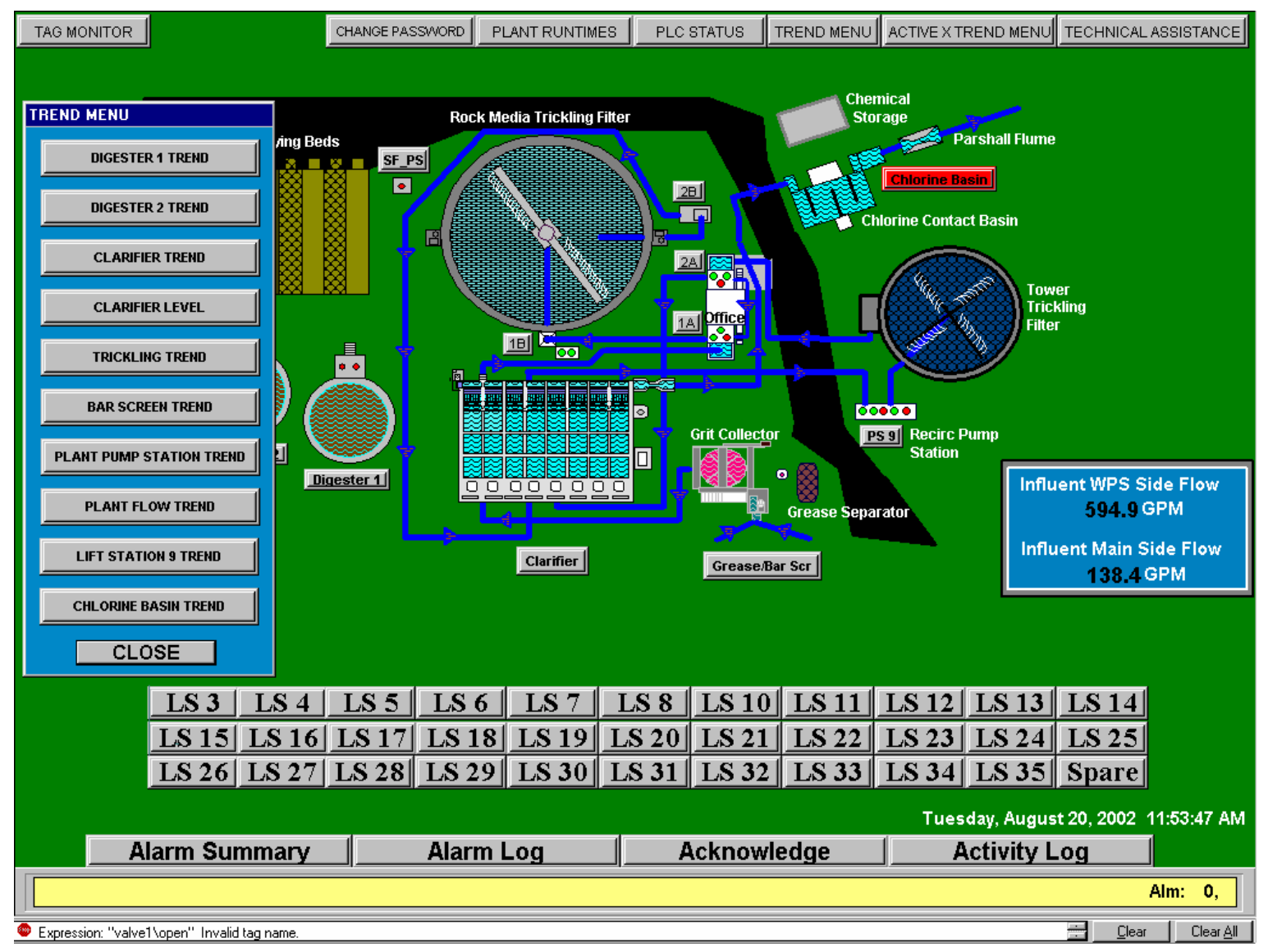

Figure A.8: Main Plant Component Trend Menu Display

This display is accessed from the Trend Menu button located along the top of the display. It provides the supervisor and operators with easy access to trend information on each of the major process components. 


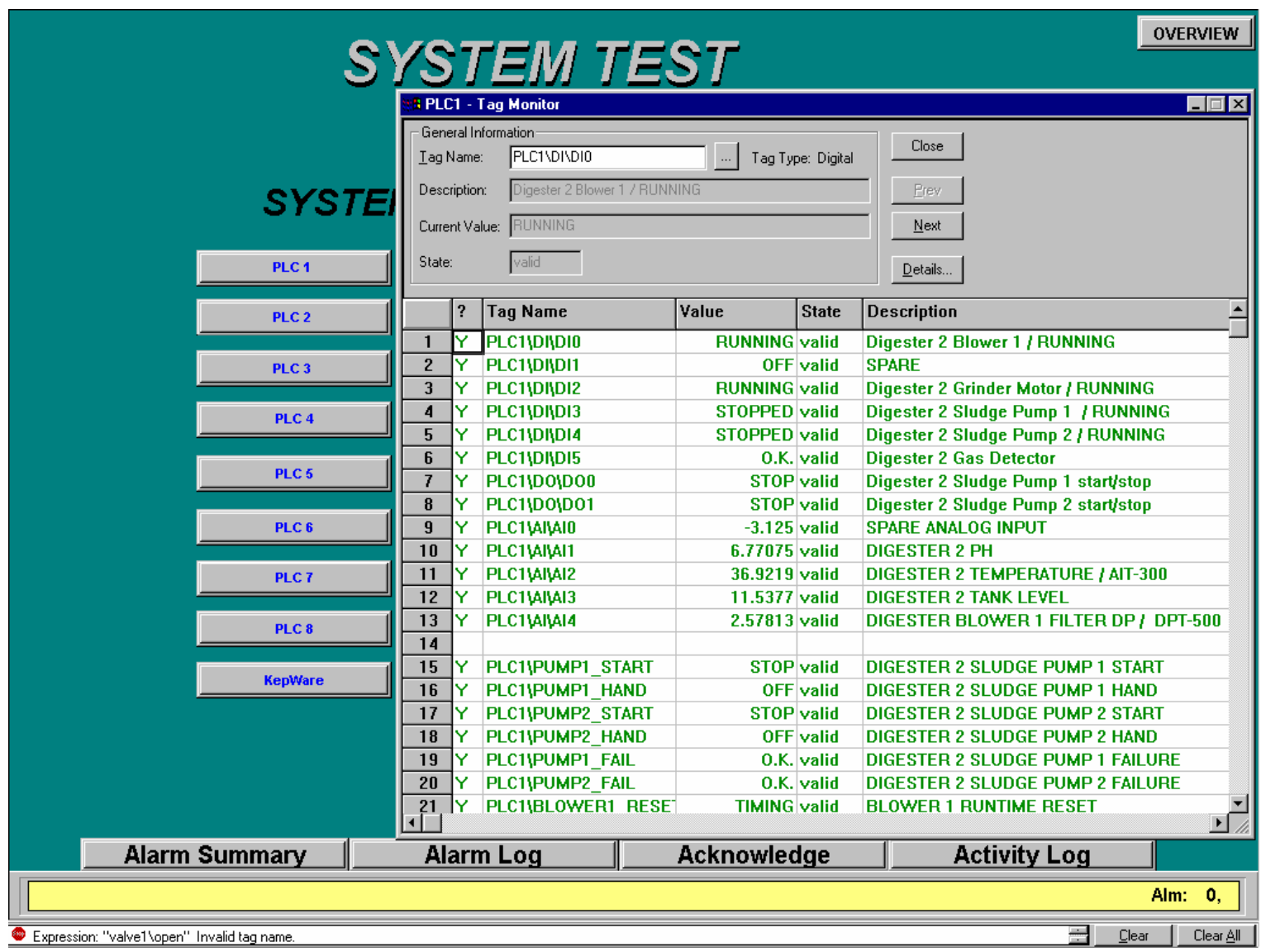

Figure A.9: Tag Monitor Display for PLC \#1

This is an example showing the status of the inputs to PLC \#1. The name, value, state and description of all input and output tags are revealed to aid in initial setup, programming, and troubleshooting communications problems if necessary. The ability to make changes in these programming screens is limited by security access rights determined by the supervisor and set in the Login permissions screen. 


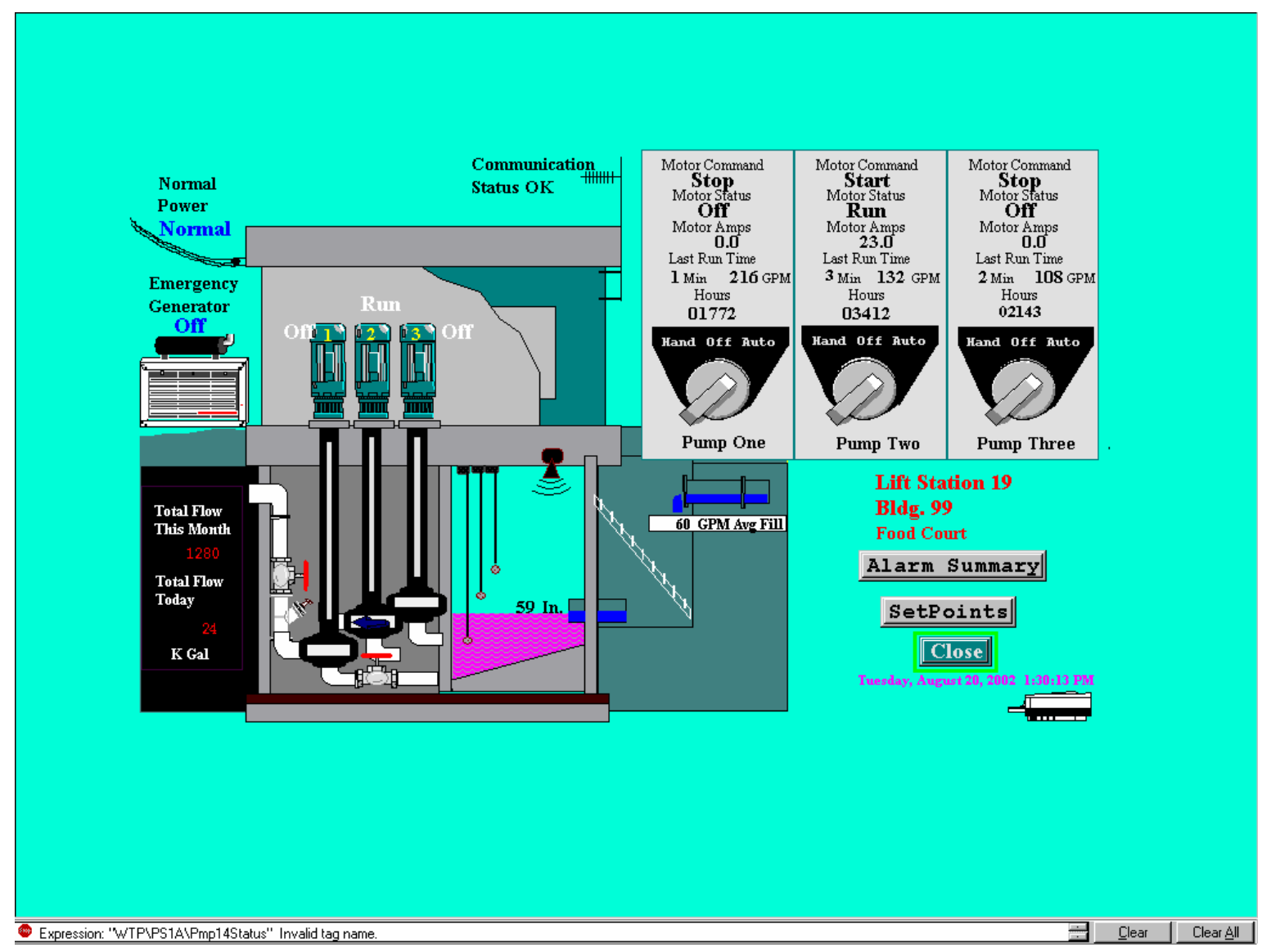

Figure A.10: Typical Lift Station Display Screen

This display indicates one of several different basic lift stations. Each one is customized to its particular attributes. Each screen includes live visual display of water level, pump, communications, and emergency generator status. Flow through each lift station is totalized by day and month. Pump control, generally in auto, can be controlled from the operator's office. The setpoints for pump control and alarms can be accessed via the set points button, which is only visible if the operator has been granted access via his login security permissions (see Figure 11). 


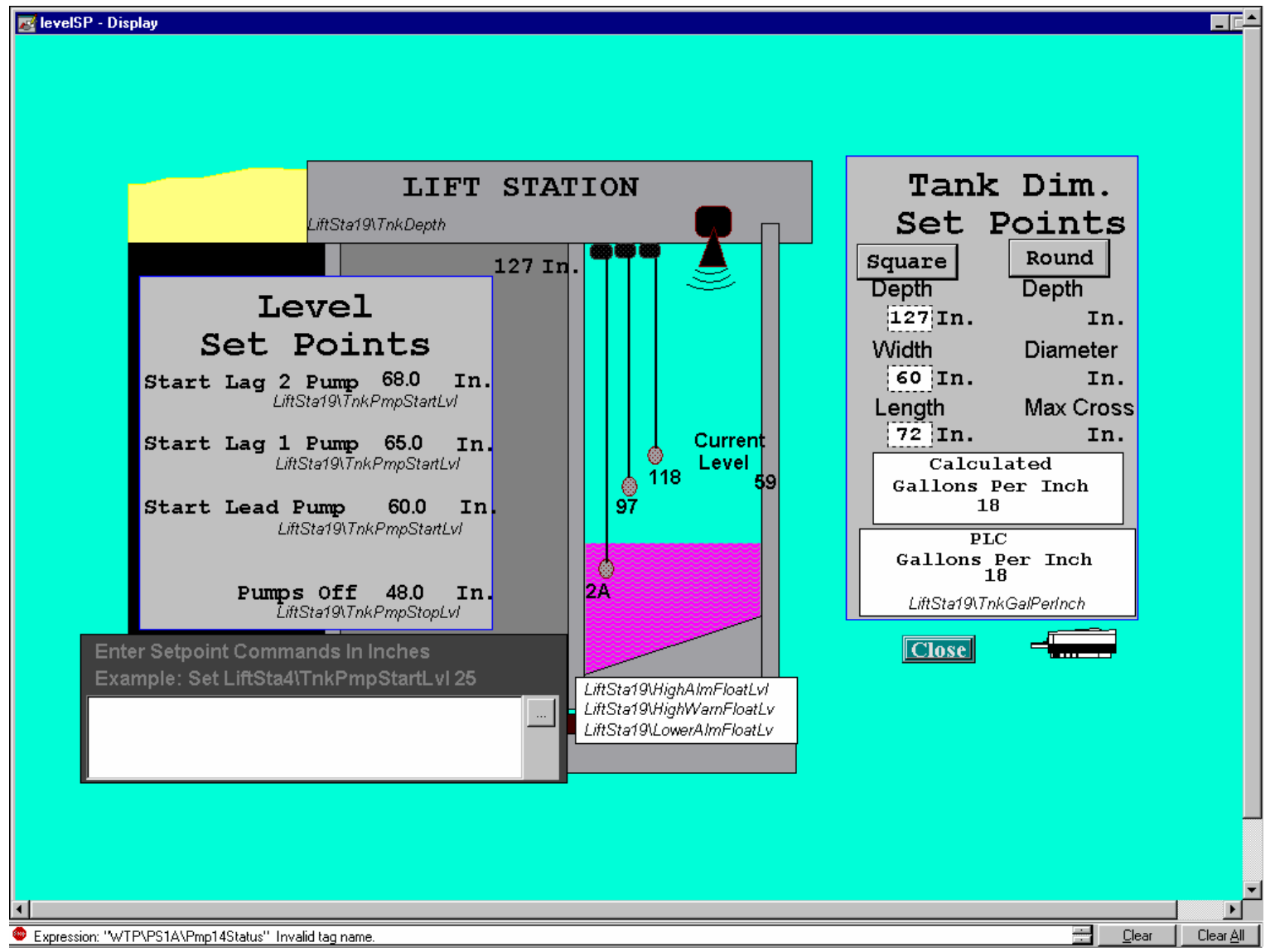

Figure A.11: Lift Station Set Point Modification Display Screen

This display allows the supervisor or designated operators to modify setpoints for each lift station or to review what the setpoints are for each lift station. This is one of the few locations where some type of manual entry is available to make changes. This screen is set up with the supervisor's input during commissioning. Although the required training is minimal, there are generally only one or two operators or support personnel trained to make inputs to this screen. Because not all lift stations are in the same configuration, allowances can be made for the number of pumps and type of tank. 


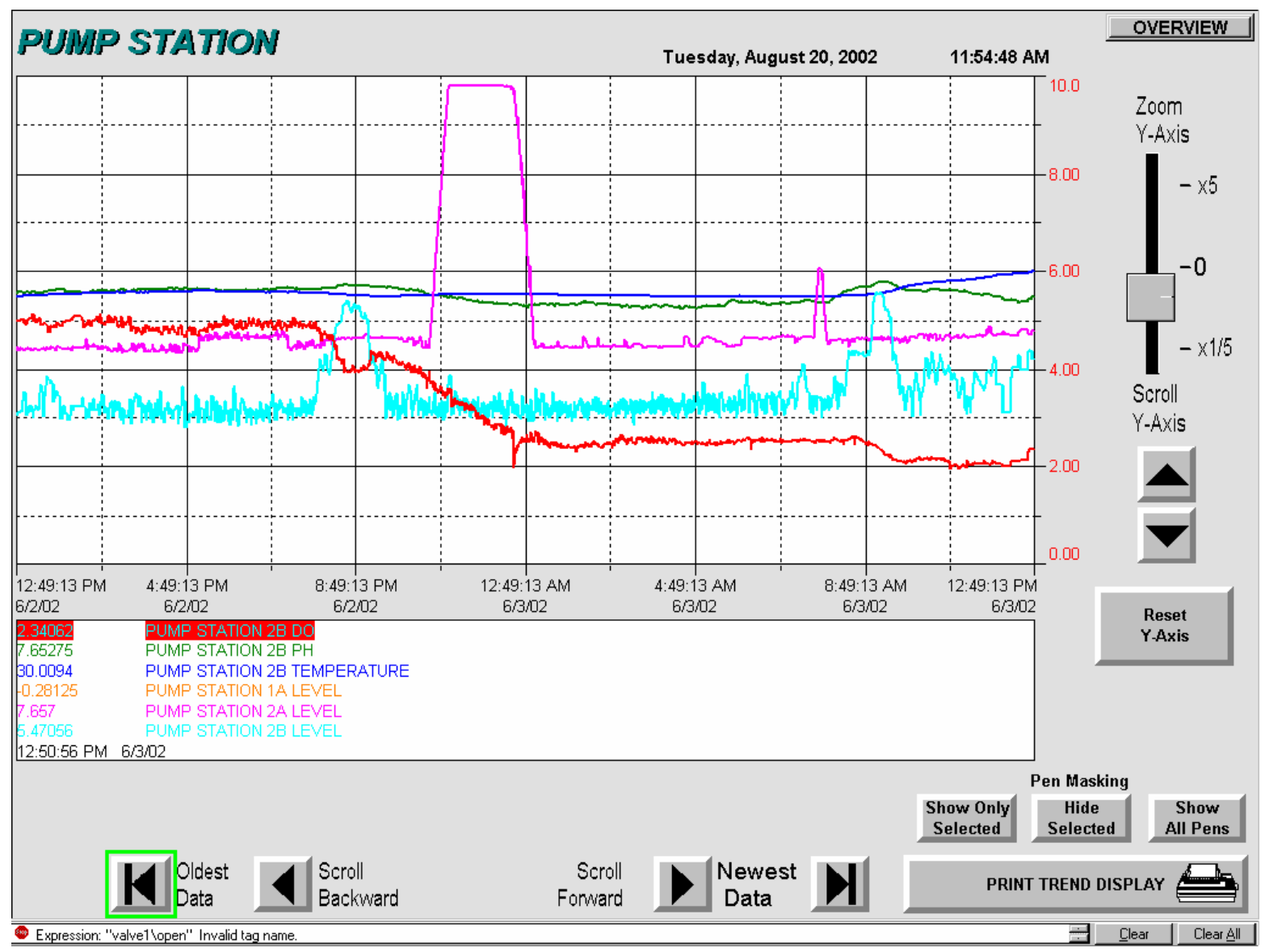

Figure A.12: Pump Station Trend Display

This trend display is showing a 24-hour period for six different parameters. This display indicates the breadth of displays available for each pump station. The number of displays can be easily determined and manipulated by the operator, allowing comparison between several different parameters at the same time or just monitoring of a single parameter. This is a valuable tool for troubleshooting and monitoring performance. The display parameters can also be easily adjusted to show different times and ranges, and printed. 


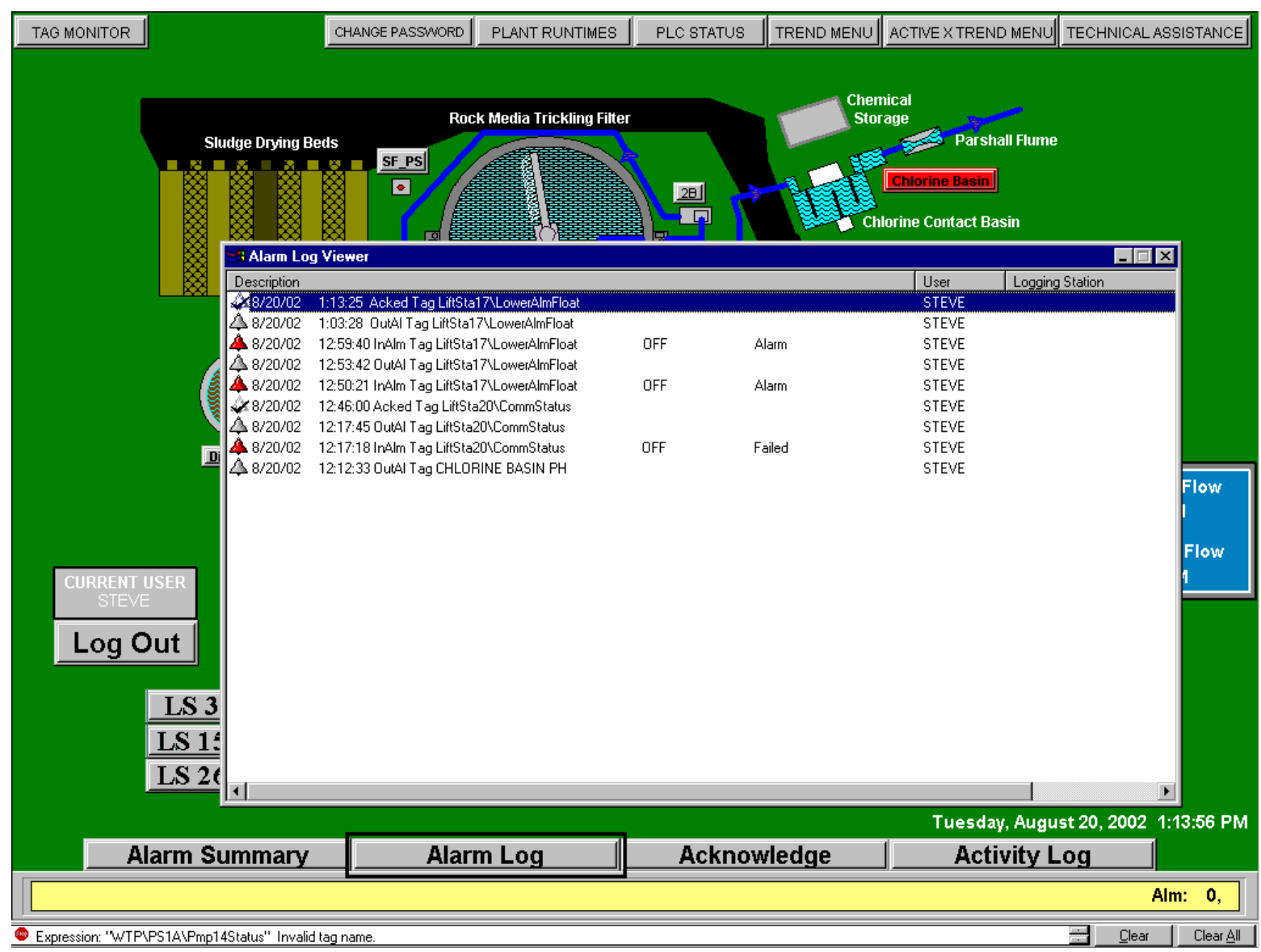

Figure A.13: The Alarm Log Viewer Display Screen

This screen, along with the Alarm Summary and Activity Log, provide a summary of alarm and activities occurring in the system. This screen provides a log summary of the tag name of the alarming signal. This allows supervisors and operators easy access to information about how frequent some alarms are and current status of all active alarms. Generally, only the current user/operator that is logged in can acknowledge alarms. 


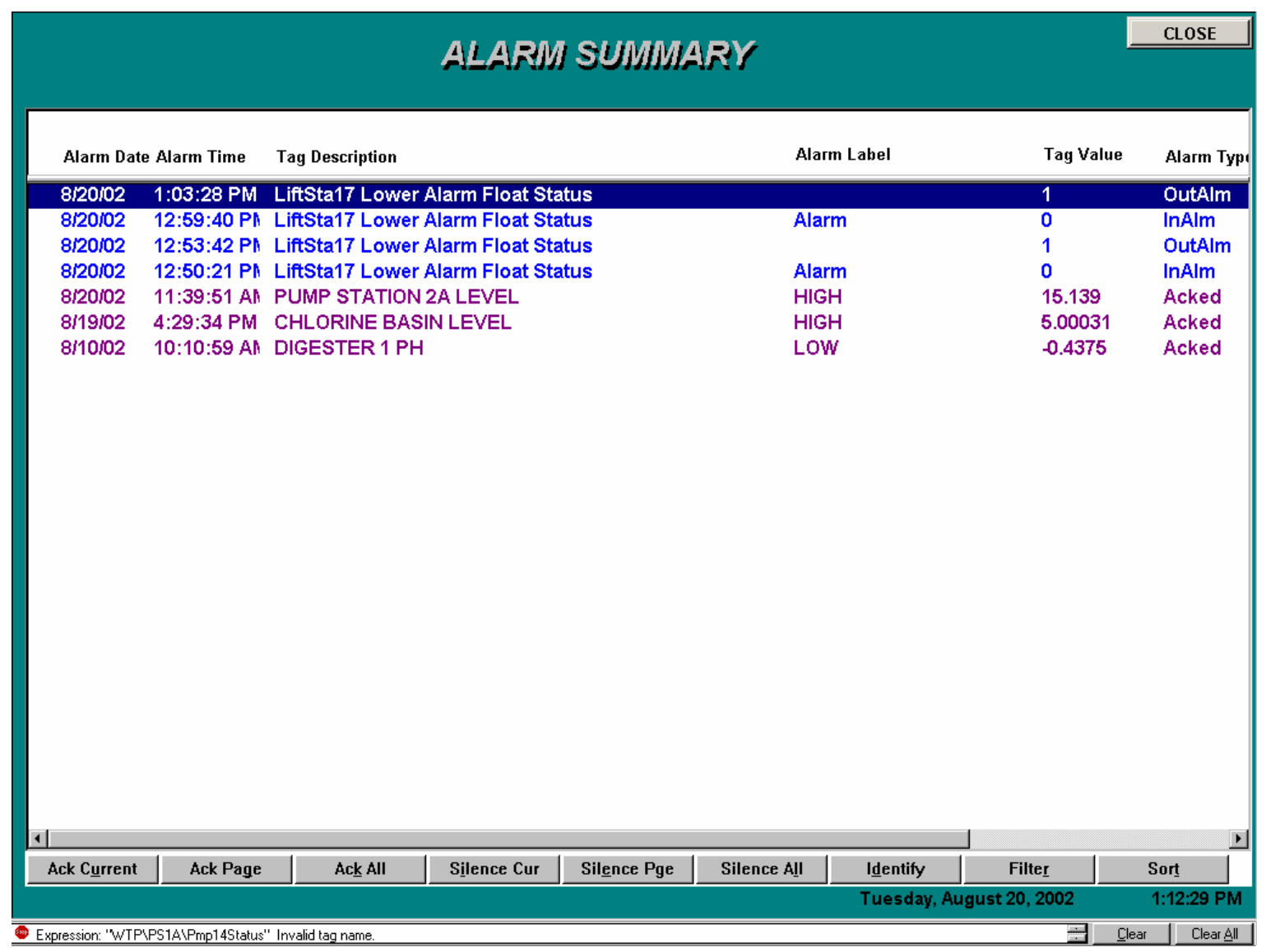

Figure A.14: The Alarm Summary Display Screen

This display summarizes all the alarms and descriptions by tag names. It also allows various options for silencing and acknowledging alarms. In the case of analog instruments, the instrument value is also provided. 